\title{
sciendo
}

REVIEWS

\section{Use of statins, amiodarone, direct oral anticoagulants and NSAIDs in chronic liver disease: a guide for general clinicians}

\author{
SEAN SILENO, RAZVAN M. CHIRILA, DANA M. HARRIS
}

Mayo Clinic Department of Internal Medicine, Jacksonville, Florida

\begin{abstract}
Patients with chronic liver disease have associated comorbidities that require treatment, including cardiovascular disease, arrhythmias, cerebrovascular accidents and pain. These medications may affect the liver disease. Due to the complexity of medical problems in patients with chronic liver disease, treating clinicians benefit from targeted guidance for their care.
\end{abstract}

Key words: liver enzymes, aminotransferases, benefits, risk factors, recommendations.

\section{INTRODUCTION}

Liver disease is an important cause of morbidity and mortality worldwide, the $11^{\text {th }}$ cause of death [1]. It is estimated that complications from cirrhosis lead to 1 million deaths annually, while another million die from viral hepatitis and hepatocellular carcinoma (HCC) [1]. Factors impacting the prevalence of chronic liver disease are diverse and include geography, demographics and history. The prevalence of alcohol consumption, viral hepatitis and obesity are key to understanding regional differences in disease prevalence [2]. In Europe, Romania has the highest prevalence of liver disease and cirrhosis out of 35 countries [2]. In the United States hepatitis C (HCV) is the leading cause of liver transplant, but non-alcoholic fatty liver disease (NAFLD) is expected to surpass given the availability of highly effective HCV treatment [3].

Due to global rise in obesity and non-insulin diabetes mellitus, a quarter of the world population has NAFLD including teenagers and young adults, and the prevalence increases [4].

These patients have multiple comorbidities particularly hypertension, diabetes, hyperlipidemia, atrial fibrillation (AF) and chronic pain treated with multiple medications. Treatment decisions become more complex as the liver disease advances, making it challenging for the treating clinician.

In this review we provide guidance for the clinician on the safety and use in chronic liver disease of statins, amiodarone, oral anticoagulants, and nonsteroidal anti-inflammatory drugs (NSAIDs).

\section{STATINS}

Statins are standard of care therapy for dyslipidemia in patients with increased cardiac risk. Statins competitively inhibit HMG-CoA reductase, the rate-limiting enzyme for endogenous cholesterol synthesis, leading to reduction of cholesterol biosynthesis. They also indirectly upregulate the expression of the LDL receptor leading to increased cholesterol uptake [7-11]. Through different pleiotropic mechanisms (Table 1), statins are beneficial in inflammation, fibrosis, endothelial function and coagulation, but the risk of hepatotoxicity is a concern in this patient population [7].

Table 1

Liver specific pleiotropic effects of statins

\begin{tabular}{cc}
\hline Liver Disease & Statin Effect \\
\hline NAFLD & $\begin{array}{c}\text { Decreased LDL/hepatic inflammation/fibrosis, inhibited } \\
\text { hepatic stellate cells (HSC) }\end{array}$ \\
\hline Chronic HCV Infection & Inhibited viral replication, Increased LDL uptake \\
\hline Hepatobiliary disease & Decreased cholesterol secretion/cholestasis \\
\hline Liver Fibrosis & Inhibited HSC activation, decreased collagen \\
\hline Cirrhosis-Induced Portal Hypertension & $\begin{array}{c}\text { Reduced portal pressure/vascular resistance, improved } \\
\text { endothelial dysfunction }\end{array}$ \\
\hline Hepatocellular carcinoma & Inhibited proliferation/ angiogenesis decreased HCC incidence \\
\hline
\end{tabular}




\section{BENEFITS OF STATINS IN CHRONIC LIVER DISEASE}

\section{Metabolic syndrome and nonalcoholic fatty liver disease}

Statins have protective mechanisms specific to liver disease. Patients with metabolic syndrome often have coexisting NALFD and an increased risk of atherosclerosis independent of traditional cardiovascular risk factors [8]. Dyslipidemia occurs in $20-80 \%$ of these patients and close to $30 \%$ of patients listed for liver transplant have significant coronary artery disease [8]. Many of these patients are on statins for cardiovascular protection.

There is no strong evidence for the use of statins in the treatment of NAFLD [8]. Studies have shown varied results. Atorvastatin $10 \mathrm{mg} /$ day over 2 years has shown benefits in NAFLD, while simvastatin $20 \mathrm{mg}$ /day over 1 year did not appear to reduce fibrosis or progression of disease [7]. A small 20 patient prospective study in which liver biopsies were taken before and after 12 months of rosuvastatin showed resolution of the steatohepatitis in 19 of the patients, but the study was limited by a lack of a control arm [8]. At the cellular level, the mechanism for decreasing fibrosis can be explained by the reduction of LDL, activation of peroxisome proliferative-activated receptor alpha (PPAR $\alpha)$ and deactivation of hepatic stellate cells (HRS) $[8,12$, 13]. Overall, more research is needed before statins can be prescribed for NAFLD alone.

\section{HEPATITIS C}

Patients with chronic hepatitis $\mathrm{C}$ have an increased risk of atherosclerosis independent of traditional cardiovascular risk factors [8]. Statins have been shown to have modest antiviral effects, particularly fluvastatin [10]. When statins are used in combination with antiviral therapy, there is a reduction in the rate of progression to cirrhosis, hepatocellular carcinoma (HCC), and overall mortality $[10,11,15]$.

\section{BILIARY DISEASE}

Patients with cholestatic liver disease have a high prevalence of hypercholesterolemia [8]. Statins have protective properties in biliary disease by reducing cholesterol synthesis and the concentration of cholesterol in bile and bile lithogenicity [7].

\section{PORTAL HYPERTENSION}

In cirrhosis induced portal hypertension, statins reduce vasoconstriction and improve microcirculation through increased production of nitric oxide $[7,10]$. Thus, statins may be an option in reducing portal hypertension in addition to beta blockers or in patients that do not respond to beta blockers. This effect has not been shown to decrease variceal rebleeding when simvastatin was studied, but it reduced mortality. The mechanism is likely multifactorial [16]. In noncirrhotic portal hypertension, statins have been found to worsen outcomes. This is likely secondary to increased angiogenesis in the splanchnic circulation [7].

\section{HEPATOCELLULAR CARCINOMA}

Statins might have antineoplastic properties, particularly in reducing the incidence of $\mathrm{HCC}$ in patients with chronic hepatitis B (HBV) and HCV. When statins are paired with nucleoside inhibitors that treat $\mathrm{HBV}$, the rate of $\mathrm{HCC}$ is reduced by $59 \%$ [10]. In patients with $\mathrm{HCC}$, a prospective trial comparing transarterial chemoembolization (TACE) with pravastatin versus TACE plus placebo found that mean survival increased from 9 to 18 months with the addition of pravastatin $[10,18]$. This effect is likely from statins' ability to reduce the metalloprotease activity in HCC. Also, statins may inhibit proliferation by inducing apoptosis of hepatoma cells and inhibiting intrahepatic angiogenesis [7]. More research is needed to understand the antineoplastic mechanism.

\section{TOXICITY OF STATINS IN CHRONIC LIVER DISEASE}

Medication induced hepatotoxicity is dependent on multiple factors including lipophilicity, solubility, absorption, and route of metabolism. The most common form of hepatotoxicity from statins is elevated transaminases, which occurs approximately $3 \%$ of the time, usually within the first week and tends to be transient even with continued use [8]. This is likely due to increased permeability of the hepatocyte membrane and leaking of liver enzymes and not due to hepatocyte damage. Liver biopsies do not show significant abnormalities. Only approximately $3 \%$ of these patients have persistent elevation of liver enzymes [8].

The risk of hepatotoxicity is higher with lipophilic statins like atorvastatin, simvastatin and fluvastatin which are metabolized through the cytochrome P450 system. Toxicity increases with increasing dose and kidney dysfunction. Hepatotoxicity 
with atorvastatin $10 \mathrm{mg}$ is $0.3 \%$ and with atorvastatin $80 \mathrm{mg} 2.3 \%$. There is less hepatotoxicity with the hydrophilic statins pravastatin and pitivastatin which undergo minimal hepatic metabolization. Rosuvastatin has an intermediate behavior [8].

More concerning than transiently elevated transaminases is drug induced liver injury (DILI), defined as ALT greater than or equal to 5 times the upper limit of normal (ULN). DILI related to statins is rare, idiosyncratic, and may occur in the first month of starting the statin up to ten years after. It has an incidence of 1.2 per 100,000 users in a large Swedish cohort or 1 per 5,000 users in smaller studies $[8,10]$. Patients with baseline elevation in aminotransferases from HCV or NAFLD, even in compensated cirrhosis, do not have a higher risk of statin-induced liver injury when compared to the general population, [6]. Therefore, if such patients have indication for statin use, a statin may be started [8].

\section{RECOMMENDATIONS FOR USE OF STATINS IN CHRONIC LIVER DISEASE}

Statins are indicated to lower lipids in patients with elevated cardiac risk, but more studies are needed to evaluate their use for pleiotropic effects. Overall, benefits of statins outweigh adverse effects and they are safe to use in compensated liver disease and in post liver transplant patients, even in patients with baseline elevation of aminotransferases. In mild cirrhosis, Child Pugh A, observational studies show an association between the use of statins and improved survival and decreased risk of liver decompensation [7]. Caution should be used when prescribing statins to patients with decompensated cirrhosis and patients with portal hypertension not secondary to cirrhosis. Transaminases are checked at the beginning of the treatment and subsequently only as clinically indicated. Lower starting doses should be considered in patients with kidney disease as they are partly excreted by the kidney.

\section{AMIODARONE}

Amiodarone is a highly effective antiarrhythmic that that has been used since the 1960s first as antianginal. Amiodarone blocks the potassium, sodium and calcium channels in the ventricular myocardium and has an antiadrenergic effect [19-23].

In the 1980s physicians began using higher doses of amiodarone to quickly control unstable arrhythmias. Reports of hepatotoxicity started to appear in the literature [19, 20]. Amiodarone's variable toxicity is related to both lipophilicity and metabolism. Oral amiodarone is slowly absorbed by the gastrointestinal tract, with variable individual bioavailability of 30 to $80 \%$ and increased absorption when taken with food. Variation in bioavailability is thought to be secondary to intestinal mucosa and hepatic first pass metabolism. Amiodarone also has a high volume of distribution due to its tendency to accumulate in lipids, liver, and lung tissue. 30-70\% of serum concentration is lost to tissues, so it takes months to reach steady-state [20,21].

\section{HEPATOTOXICITY}

The precise mechanism of amiodarone toxicity is unknown, but may be related to reactive oxygen species formed [17]. Hepatotoxicity appears as mild elevation of transaminases and alkaline phosphatase, without associated elevated bilirubin or decline in the liver's synthetic function. Clinical hepatitis, cirrhosis, and death have been reported but are rare [20, 22-23]. Histologically hepatotoxicity appears similar to alcoholic hepatitis with Mallory bodies; however the presence of lamellar lysosomal inclusion bodies is unique to amiodarone toxicity [20, 23, 24].

Estimates of the prevalence of hepatotoxicity vary and are difficult to quantify as liver biopsy is only obtained in the most severe cases. When defining asymptomatic transaminase elevation AST/ALT 4 times the upper limit of normal, amiodarone induced liver toxicity has a prevalence of $23 \%$ [25]. Generally, hepatotoxicity is reversible by stopping amiodarone or by lowering the dose, however toxicity can continue due to amiodarone's accumulation in the body's tissues. Clinically severe liver disease occurs in $1-3 \%$ of patients [20].

Hepatoxicity is directly related to serum concentrations of amiodarone. Patients with concentrations $>2.5 \mathrm{mg} / \mathrm{L}$ have a $7 \%$ chance of developing ALT $>3 \times$ ULN, while patients with a serum concentration $<1.5 \mathrm{mg} / \mathrm{L}$ have minimal risk [20, 23, 24]. A dose of $150-300 \mathrm{mg} /$ day is not likely to cause toxicity. The loading dose of amiodarone and the initial intravenous high dose administered in acute arrhythmias has been associated with the highest risk for hepatotoxicity, but correlation between the IV preparation and liver injury is difficult to establish since polysorbate 80 solvent is a known hepatotoxic compound [20].

\section{RECOMMENDATIONS FOR USE OF AMIODARONE IN CHRONIC LIVER DISEASE}

Obtain liver function labs prior to starting therapy to establish a baseline. Start with the lowest 
effective dose and decrease the dose once the arrhythmia is under control. AST and ALT should be checked at one month, and subsequently ALT should be drawn every 3 months for the first year and every 6 months thereafter. The threshold for discontinuing therapy is based on guidelines from the North American Society of Pacing and Electrophysiology, which recommends discontinuing amiodarone if the ALT is greater than 2 times the ULN [27].

In chronic liver disease guidance for amiodarone use is limited, but patients with ALT 2 times ULN are safe in taking amiodarone. In a study of those patients, ALT increased in $4.4 \%$ vs $3.7 \%$ of patients with normal starting ALT and no patients developed fulminant hepatitis [28].

Amiodarone therapy in patients with chronic liver disease and cirrhosis should be used with caution and with close monitoring. The lowest dose necessary should be used and perhaps only be considered once other therapies for arrhythmias have failed [17]. A dose of $150-330 \mathrm{mg} /$ day is preferred as it is unlikely to cause toxicity.

\section{ORAL ANTICOAGULANTS}

Anticoagulants are prescribed to patients with chronic liver disease for the same indications as in patients without liver disease, but precautions must be taken. Chronic liver disease and cirrhosis lead to an inherent coagulopathy resulting from the imbalance of procoagulant and anticoagulants proteins produced by the liver. Despite often having elevated INR, patients with chronic liver disease have higher than baseline occurrence of stroke and venous thromboembolism (VTE), but also a higher likelihood of bleeding.
The decreased production of proteins $\mathrm{C}$ and $\mathrm{S}$ and antithrombin, decreased activity of plasminogen and increased production of Factor VIII, von Willebrand factor, and ADAMTS 13 lead to an environment that favors clotting [26]. The most common thrombosis in cirrhotic patients is portal vein thrombosis, occurring at a rate of $8-18 \%$ [29]. There is a 2.5 times higher risk of ischemic stroke and 2 times higher risk of VTE in patients with liver disease compared with patients without liver disease. These patients have 2 times the risk of mortality from the thromboembolism, and the ischemic stroke is associated with poor prognosis and increased in-hospital death [30, 31].

Coagulopathy of chronic liver disease increases bleeding risk secondary to low platelet count and platelet dysfunction, low production of fibrinogen and factors II, V, VII, IV, X, XI, and increased activity of fibrinolytic proteins such as tissue plasminogen activator $[29,30]$.

\section{RECOMMENDATIONS FOR USE OF ORAL ANTICOAGULANTS IN CHRONIC LIVER DISEASE}

The choice of oral anticoagulants used in liver disease is based on the degree of cirrhosis guided by the Child-Pugh score. This score takes into account total bilirubin, albumin, INR, ascites, and encephalopathy. Following dosing guidance from the American Food and Drug Administration (FDA) and the European Medicines Agency (EMA), patients with Child-Pugh class A are eligible for all classes of oral anticoagulants including novel oral anticoagulants (NOACs) and warfarin. For ChildPugh class $\mathrm{C}$ only warfarin is an option, while in class B warfarin is the preferred choice, but certain NOACs can be used with caution (see Table 2).

Table 2

Summary of EMA Recommendations for the Use of Oral Anticoagulants in Chronic Liver Disease in Patients with Patients with VTE or AF [28, 29, 35-38]

\begin{tabular}{|c|c|c|}
\hline Oral Anticoagulant Agent & Child-Pugh Class & EMA Recommendation \\
\hline \multirow{3}{*}{ Warfarin } & $\mathrm{A}$ & \multirow{3}{*}{ Therapeutic INR (2.0-3.0) } \\
\hline & B & \\
\hline & $\mathrm{C}$ & \\
\hline \multirow{3}{*}{ Apixaban } & $\mathrm{A}$ & \multirow{2}{*}{ Use with caution, but no dose adjustment } \\
\hline & $\mathrm{B}$ & \\
\hline & $\mathrm{C}$ & Not recommended \\
\hline \multirow{3}{*}{ Dabigatran } & $\mathrm{A}$ & \multirow{3}{*}{$\begin{array}{l}\text { Not recommended if AST/ALT }>2 \mathrm{x} \\
\text { ULN or if liver disease expected to affect } \\
\text { survival }\end{array}$} \\
\hline & $\mathrm{B}$ & \\
\hline & $\mathrm{C}$ & \\
\hline \multirow{3}{*}{ Edoxaban } & $\mathrm{A}$ & \multirow{3}{*}{$\begin{array}{c}\text { No dose adjustment } \\
\text { Use with caution, if AST/ALT }>2 \mathrm{x} \text { ULN } \\
\text { or total bilirubin }>1.5 \times \text { ULN }\end{array}$} \\
\hline & $\mathrm{B}$ & \\
\hline & $\mathrm{C}$ & \\
\hline \multirow{3}{*}{ Rivaroxaban } & $\mathrm{A}$ & No dose adjustment \\
\hline & $\mathrm{B}$ & \multirow{2}{*}{ Not recommended } \\
\hline & $\mathrm{C}$ & \\
\hline
\end{tabular}


Table 3

Recommendations for Statins, Amiodarone, and NSAIDs in Chronic Liver Disease

\begin{tabular}{|c|c|c|c|}
\hline & Chronic Liver Disease & Compensated Cirrhosis & Decompensated Cirrhosis \\
\hline Statins & \multicolumn{2}{|c|}{$\begin{array}{l}\text { - Indicated in dyslipidemia and elevated cardiac risk } \\
\text { - Obtain baseline liver function tests before starting therapy and only repeat } \\
\text { if clinically indicated }\end{array}$} & $\begin{array}{l}\text { - Statins should be used with } \\
\text { cation }\end{array}$ \\
\hline Amiodarone & \multicolumn{3}{|c|}{$\begin{array}{l}\text { - Use with caution in all liver disease } \\
\text { - AST and ALT should be checked at baseline and one month, then ALT every } 3 \text { months for the first year } \\
\text { then every } 6 \text { indefinitely } \\
\text { - Discontinue if the ALT is greater than } 2 \times \text { ULN }\end{array}$} \\
\hline NSAIDs & - Contraindicated except aspirin & \multicolumn{2}{|c|}{$\begin{array}{l}\text { - Aspirin for primary/ secondary prevention should be used } \\
\text { with caution in cirrhosis }\end{array}$} \\
\hline
\end{tabular}

There is limited prospective data that establishes an INR goal in patients with chronic liver disease on warfarin, however a goal of 2.0 to 3.0 is usually used. In retrospective studies, warfarin has been shown to be beneficial in preventing stroke in patients with liver disease and atrial fibrillation. Treatment with warfarin of portal vein thrombosis increases the rate of portal vein recanalization [30].

NOACs are increasingly becoming first-line therapy for VTE and AF due to their ease of use and favorable safety profile. NOACs have varying dependence on hepatic metabolism causing the exclusion of patients with cirrhosis from large NOAC studies. Current literature guiding their use in this patient population relies on metabolism studies rather than clinical trials [30, 32-34]. Recent literature has shown that NOACs are safe for patients with cirrhosis when compared to warfarin and even have lower rates of major bleeding [32-34].

Before starting any oral anticoagulant a bleeding assessment is necessary by obtaining a thorough history of previous bleeding, current alcohol usage and NSAIDs. Baseline liver function laboratories need to be obtained and endoscopic screening for varices should be completed [30]. Patients with peptic ulcer disease (PUD), portal hypertensive gastropathy (PHG) or varices benefit from proton pump inhibitor prophylaxis.

Overall, oral anticoagulants should not be withheld from patients with chronic liver disease when anticoagulation is indicated. While warfarin has been the mainstay of treatment of AF and VTE in chronic liver disease, more recent studies show that NOACs are safe and effective.

NSAIDs

Nonsteroidal anti-inflammatory drugs (NSAIDs) are a broad class of medications that inhibit either cyclooxygenase 1 (COX-1), cyclooxygenase 2 (COX-2), or both. NSAIDs have many indications, but are primarily used for their pain relieving and antipyretic properties. Unfortunately, NSAIDs have numerous side effects that limit their use including renal dysfunction, gastrointestinal mucosal damage, and cardiac ischemia.

\section{NSAIDs IN CHRONIC LIVER DISEASE}

One of the most serious complications of cirrhosis is hepatorenal syndrome. Portal hypertension leads to vasodilation of the splanchnic vasculature and decreased renal perfusion. To increase perfusion at the kidneys, the renin-angiotensin-aldosterone system (RAAS) is activated. NSAIDs interfere with production of prostaglandins that help maintain renal perfusion, which could precipitate or worsen already present hepatorenal syndrome. Also, due to increased RAAS activity, patients with chronic liver disease develop volume retention manifesting as ascites and dependent edema. Normally this is treated with a loop diuretic, but NSAIDs can make loop diuretics significantly less effective $[35,36]$.

In the stomach, NSAIDs decrease the concentration of protective prostaglandins that leads to an increased risk of gastritis and ulcers. NSAIDs also decrease platelet aggregation by reducing the concentration of thromboxane $\mathrm{A}_{2}$. This combined with coagulopathy and thrombocytopenia leads a significantly increased risk of gastrointestinal bleeding $[35,36]$.

\section{RECOMMENDATIONS FOR USE OF NSAIDs IN CHRONIC LIVER DISEASE}

In general NSAIDs are not recommended in cirrhosis due to the increased risk of renal failure and bleeding. In early liver disease NSAIDs should be used very cautiously. Patients with NAFLD often take aspirin for cardioprotection, however the risks and benefits of aspirin should be examined when 
the liver disease advances to cirrhosis. Currently there is limited information supporting the safety of COX-2 inhibitors in chronic liver disease, so they should be used with caution and be avoided in cirrhosis [36].

\section{CONCLUSION}

Patients with chronic liver disease have numerous complex medical problems treated with multiple medications. Practicing clinicians are continuously faced with decisions regarding the safety of those treatments. Statins are safe if indicated for hyperlipidemia and there is mortality benefit. Baseline elevation of transaminases is not a contraindication to therapy. As more evidence becomes available, statins may be used for indications based on their favorable pleiotropic effects.
Amiodarone hepatotoxicity does not increase in patients with baseline liver disease if serum concentrations are low. A dose of $150-300 \mathrm{mg}$ /day is safe. ALT should be checked every 3 months for the first year and then every 6 months moving thereafter. Amiodarone should be stopped if ALT increases to greater than 2 times ULN.

Oral anticoagulants are safe and efficacious in patients with chronic liver disease. Warfarin dosing is based on INR. The choice of oral anticoagulation is based on Child-Pugh score. Risk factors for bleeding should be optimized before the start of therapy.

NSAIDs are not a safe choice in patients with chronic liver disease due to the significant risk of hepatorenal syndrome and bleeding. In patients with NAFLD, aspirin used in cardiac primary/ secondary prevention is safe, but is to be used with caution if the patient progresses to cirrhosis.

Pacienții cu boală hepatică cronică asociază numeroase comorbidităţi ce necesită tratament (printre acestea se numără şi diferite afecțiuni cardiovasculare, aritmii, accidente vasculare cerebrale), iar medicamentele pot afecta boala hepatică. Având în vedere complexitatea problemelor medicale ale pacienţilor cu boală hepatică cronică clinicienii vor beneficia de ghidare pentru un management mai bun.

Correspondence to: Dana Harris, MD, 4500 San Pablo Road, South, Jacksonville, FL 32224, USA

Phone: +19045712982

FAX: +19049536722

E-mail: Harris.Dana@mayo.edu

Acknowledgments: None

Conflict of interest disclosure: The authors declare that there are no conflicts of interest.

\section{REFERENCES}

1. ASRANI S., DEVARBHAVI H., EATON J., KAMATH P. Burden of liver diseases in the world. J Hepatol. 2019; 70(1):151-171.

2. PIMPIN L., CORTEZ-PINTO H., NEGRO F. Burden of liver disease in Europe: Epidemiology and analysis of risk factors to identify prevention policies. J Hepatol. 2018; 69(3):718-735.

3. CHEDID, M. Nonalcoholic Steatohepatitis: The Second Leading Indication for Liver Transplantation in the USA. Dig Dis Sci. 2017; 62:2621-2622.

4. DOYCHEVA I., WATT K., RIFAI G. Increasing Burden of Chronic Liver Disease Among Adolescents and Young Adults in the USA: A Silent Epidemic. Dig Dis Sci. 2017; 62(5):1373-1380.

5. HEIDELBAUGH J., BRUDERLY M. Cirrhosis and chronic liver failure: Part I. Diagnosis and evaluation. Am Fam Physician. 2006; 74(5):756-762.

6. YOUNOSSI Z., STEPANOVA M., YOUNOSSI Y., GOLABI P., MISHRA A., RAFIQ N., et al. Epidemiology of chronic liver diseases in the USA in the past three decades. Gut. 2020; 69:564-568.

7. SCHIERWAGEN R., USCHNER F., MAGDALENO F., KLEIN S.,TREBICKA J. Rationale for the use of statins in liver disease. Am J Physiol Liver Physiol. 2017; 312:407-412.

8. MOCTEZUMA-VELAZQUEZ C., ABRALDES J., MONTANO-LOZA A. The Use of Statins in Patients with Chronic Liver Disease. Curr Treat Options Gastro. 2018; 16:226-240.

9. VARGAS J., ARRESE M., SHAH V., ARAB J. Use of Statins in Patients with Chronic Liver Disease and Cirrhosis: Current Views and Prospects. Curr Gastroenterol Rep. 2017; 19(9):43.

10. JANICKO M., DRAZILOVA S., PELLA D., FEDACKO J., JERCUSKA P. Pleiotropic effects of statins in the diseases of the liver. World J Gastroenterol. 2016; 22(27):6201-6213. 
11. KUMAR S., GRACE N., QAMAR A. Statin Use in Patients with Cirrhosis: A Retrospective Cohort Study. Dig Dis Sci. 2104; 59:1958-1965.

12. SAKAMOTO K., KIMURA J. Mechanism of Statin-Induced Rhabdomyolysis. J Pharmacol Sci. 2013; 123:289-294.

13. FARIGON, S., PORZIO, M., FRACANZANI A. Nonalcoholic fatty liver disease and vascular disease: State-of-the-art. World J Gastroenterol. 2014; 20(37)13306-13324.

14. DONGIOVANNI P., PETTA A., MANNISTRO V., MANCINA R., PIPITONE R., VALENTI L., et al. Statin use and non-alcoholic steatohepatitis in at risk individuals. Journal of Hepatology. 2015; 63:705-712.

15. IKEDA M., ABEK., YAMADA M., DANSAKO H., KATO N. Different anti-HCV profiles for statins and their potential for combination therapy with interferon. Hepatology. 2006; 44(1):117-125.

16. ABRALDES, J., VILLANUEVA C., ARACIL C., TURNES J., HERNANDEZ-GUERRA M., et a; Addition of Simvastatin to Standard Therapy for the Prevention of Variceal Rebleeding Does Not Reduce Rebleeding but Increases Survival in Patients With Cirrhosis. Gastroenterology. 2016; 150:1160-1170.

17. SIMON T., BONILLA H., CHUNG R., BUTT A. Atorvastatin and fluvastatin are associated with dose-dependent reductions in cirrhosis and hepatocellular carcinoma, among patients hepatitis c virus: results from ERCHIVES. Hepatology. 2016; 64(1):47-57.

18. KAWATA S., YAMASAKI E., NAGASE T., INUI Y., ITO N., MATSUDA Y., et al. Effect of Pravastatin on Survival in Patients with Advanced Hepatocellular Carcinoma. A Randomized Control Trial.Br J Cancer. 2001; 84:886-891.

19. CONNOLLY S. Evidence-based analysis of amiodarone efficacy and safety. Circulation. 1999; 100(19):2025.

20. BABATIN, M., LEE S., POLLAK P. Amiodarone Hepatotoxicity. Current Vascular Pharmacology. 2008; 6:228-236.

21. POLLACK P., BOUILLON T., SHAFER S. Population pharmacokinetics of long-term oral amiodarone therapy. Clin Pharmacol Ther. 200; 67:642-652.

22. MATTAR W., GADUS-PIZLO I., KWO P. Amiodarone Hepatotoxicity in the Context of the Metabolic Syndrome and Rightsided Heart Failure. Gastrointestin Liver Dis. 2009; 18(4):419-423.

23. PENDYALA V. A case of Amiodarone-induced Hepatitis and Review of the Literature. J Hepatol Gastroint Dis. $2016 ; 2: 120$.

24. SUNG P., YOON S. Amiodarone Hepatotoxicity. Hepatology. 2012; 1:326.

25. LEWIS J., RANARD R., CARUSO A., JACKSON L., MULLICK F., ISHAK K., et al. Amiodarone hepatotoxicity: prevalence and clincopathologic correlations among 104 patients. Hepatology. 1989; 9:679-685.

26. ATIQ M., DAVIS J., LAMPS L., BLENAD S., ROSE L. Amiodarone induced liver cirrhosis, Report of two cases. J Gastrointestin Liver Dis. 2009; 18:233-235.

27. GOLDSCHLAGER N., EPSTEIN A., NACCARELLI G., OLSHANSKY B., SINGHB. Practical guidelines for clinicians who treat patients with amiodarone. Practice guidelines subcommittee, North American Society of Pacing and Electrophysiology. Arch Intern Med. 2000; 160:1741-1748.

28. KUM L., CHAN W., HUI H., WONG G., HO S., SANDERSON J., et al. Prevalence of amiodarone-related hepatotoxicity in 720 Chinese Patients with or without baseline liver dysfunction. Clin Cardiol. 2006; 29:295-299.

29. TRIPODI A., MUNUCCIP. The coagulopathy of chronic liver disease. N Engl J Med. 2011; 365:147-156.

30. QAMAR A., VADUGANATHAN M., GREENBERGER N., GIUGLIANO R. Oral anticoagulants in patients with liver disease. JAM Coll Cardiol. 2018; 71(19)2162-2175.

31. LING K., CHAO T., LIU C., LIN Y., CHANG S., LO L., HU Y., TUAN, T., et al. Liver cirrhosis in patient with atrial fibrillation: would oral anticoagulation have a net clinical benefit for stroke prevention? J Am Herat Assoc. 2017; 6(6).

32. GORIACKO P. VELTRI K. Safety of direct oral anticoagulants vs warfarin in patients with chronic liver disease and atrial fibrillation. Eur J Haematol. 2018; 100(5):488-493.

33. HUM J., SHATZEL J., JOU J., DELOUGHERY T. The efficacy and safety of direct oral anticoagulants vs traditional anticoagulants in cirrhosis. Eur J Haematol. 2017; 98:393-397.

34. INTAGLiata N., HENRY Z., MAITLAND H., SHAH N., MATILANDS H., SHAH N., ARGO C., NORTHUP P., CALDWELL S. Direct oral anticoagulants in cirrhosis patient pose similar risks of bleeding when compared to traditional anticoagulation. Dig Dis Sci. 2016; 61:1721-1727.

35. MALESPIN M. Risk of nonsteroidal anti-inflammatory drugs and safety of acetaminophen in patients with advanced liver disease. Clin Liver Dis. 2018; 12(3):85-88.

36. CHANDOK N., WATT K. Pain management in the cirrhotic patient: The clinical challenge. Mayo Clin Proc. 2010; 85(5):451-458.

37. Eliquis (apixaban) [package insert]. Bristol-Myers Squibb. New York, NY; 11/2019. [cited May 14/2020]. Available from: $\mathrm{http} / / /$ packageinserts.bms.com/pi/pi_eliquis.pdf.

38. Pradaxa (dabigatran etexilate) [package insert]. Boehringer Ingelheim Pharmaceuticals Inc. Ridgefield, CT; 11/2019 [cited May 14, 2020]. Available from: https://docs.boehringer-ingelheim.com/Prescribing\%20Information/PIs/Pradaxa/Pradaxa.pdf.

39. Savaysa (edoxaban) [package insert]. Daiichi Sankyo. Tokyo, Japan. 1/2015 [cited May 14/2020]. Available from: https:// www.accessdata.fda.gov/drugsatfda_docs/label/2015/206316lbl.pdf.

40. Xarelto (rivaroxaban) [package insert]. Janssen Pharmaceuticals Inc. Titusville, NJ; 03/2020 [cited May 14/2020]. Available from: https://www.xareltohcp.com/shared/product/xarelto/prescribing-information.

Recieved $4^{\text {th }}$ June 2020 